\title{
Phylogeny and polymorphism in the E6 and E7 of human papillomavirus: alpha-9 (HPV16, 31, 33, 52, 58), alpha-5 (HPV51), alpha-6 (HPV53, 66), alpha-7 (HPV18, 39, 59, 68) and alpha-10 (HPV6, 44) in women from Shanghai
}

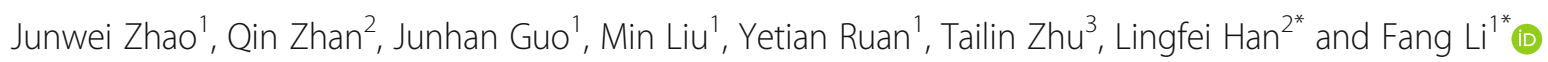

\begin{abstract}
Background: Persistent infection with human papillomaviruses (HPVs) has been associated with cervical intraepithelial neoplasia (CIN) and cervical cancer. However, why only a fraction of HPV cases progress to cancer is still unclear.

Methods: We focused on the heterogeneity, classification, evolution and dispersal of variants for 14 common HPV types in 262 HPV-positive patients with cervical lesions. The E6 and E7 genes of HPV were sequenced and compared with the HPV reference for sequence analysis. Phylogenetic trees were constructed using the neighbourjoining tree method with MEGA 7.0.

Results: In this study, 233 E6 and $212 E 7$ sequences were successfully amplified by PCR, and these sequences were divided into 5 species groups: alpha-9 (HPV16, 31, 33, 52, 58), alpha-5 (HPV51), alpha-6 (HPV53, 66), alpha-7 (HPV18, $39,59,68)$ and alpha-10 (HPV6, 44). The incidence of high-grade squamous intraepithelial lesion (HSIL) in patients infected with alpha-9 HPV was significantly increased compared with other groups $(P<0.0001)$, especially HPV16 $(P<0.0001)$. Strikingly, E7 had significantly fewer nonsynonymous variants in the HSIL compared to $<$ HSIL groups $\left(P=3.17 \times 10^{-4}\right)$. The A388C (K93 N) variation in HPV58 E6 can significantly reduce the risk of HSIL $(P=0.015)$. However, T7220G (D32E) variation in HPV16 E6 and A7689G (N29S) in HPV16 E7 increased the incidence of HSIL compared to the $<$ HSIL group ( $P=0.036$ and 0.022 ).
\end{abstract}

Conclusions: Strict conservation of E7 is important for HPV carcinogenicity, especially N29 of HPV16. The findings in this work provide preventative/therapeutic interventions for HPV infections and CIN.

Keywords: Human papillomavirus, Cervical intraepithelial neoplasia, E6 and E7 gene, Genetic variations, Polymorphism analysis

\footnotetext{
* Correspondence: lingfeihan@126.com; fang_li@tongji.edu.cn

Department of Gynecology, Shanghai First Maternity and Infant Hospital,

Tongji University School of Medicine, Shanghai 201204, China

${ }^{1}$ Department of Obstetrics and Gynecology, East Hospital, Tongji University

School of Medicine, 150 Jimo Rd, Shanghai 200120, People's Republic of

China

Full list of author information is available at the end of the article
}

(c) The Author(s). 2019 Open Access This article is distributed under the terms of the Creative Commons Attribution 4.0 International License (http://creativecommons.org/licenses/by/4.0/), which permits unrestricted use, distribution, and reproduction in any medium, provided you give appropriate credit to the original author(s) and the source, provide a link to the Creative Commons license, and indicate if changes were made. The Creative Commons Public Domain Dedication waiver (http://creativecommons.org/publicdomain/zero/1.0/) applies to the data made available in this article, unless otherwise stated. 


\section{Background}

Currently, over 200 types of HPV have been fully characterized, of which the great majority clusters phylogenetically within three genera of the Papillomaviridae family: alpha $(\alpha)$, beta $(\beta)$, and gamma $(\gamma)$ [1]. The $\alpha$ genus contains HPV types that infect mostly mucosal and genital regions, including 65 papillomavirus types from humans, and this group of viruses constitutes 14 species groups [2]. Persistent HPV infections are considered the material cause of cervical cancer, where greater than $99 \%$ of cervical cancer lesions contain HPV DNA [3]. At least 3 ancestral papillomaviruses are responsible for the current heterogeneous groups of genital HPV genomes, including low-risk (LR) 1 ( $\alpha 1,8,10$ and 13), LR2 $(\alpha 2,3,4$ and 14) and high-risk (HR) ( $\alpha 5,6,7,9$ and 11) [2].

However, why only a small proportion of HPV infections progressed to precancer and cancer is unclear [4]. In addition to the pathogenic heterogeneity of distinct HPV types, previous studies indicate that HPV variants are also associated with different risks of cancer progression. For example, the HPV16 variant has significantly different risks of HPV persistent infection, progression to cervical intraepithelial neoplasia (CIN) and cervical cancer [5, 6]. Lisa Mirabello observed that compared to the most frequent A1/A2 sublineages, the A4, C, D2 and D3 sublineages conferred a higher hazard of CIN and cervical cancer [7]. The $\mathrm{C}$ variant (vs. B variant) of HPV52 was associated with an increased prevalence of cytologically diagnosed and histologically confirmed HSIL or worse lesions [8]. These data indicate that HPV variants have different phenotypic characteristics, including carcinogenicity.

HPV E6 and E7 are the major oncogenes, which are highly expressed in tumours and are related to inducing cellular immortalization, transformation, and carcinogenesis through protein-protein interactions with tumour suppressor proteins [9]. For example, E6 binds the conserved LxxLL consensus sequences of the ubiquitin ligase E6-associated protein (E6-AP), which works as a connecting bridge between $\mathrm{E} 6$ and p53, leading to its subsequent degradation [10]. Similarly, E7 targets and promotes the inactivation of RB1, thus inducing cell-cycle progression through activation of E2F-driven transcription [11].

In this study, we focused on the phylogeny and polymorphism of E6 and E7 gene variants for 14 common HPV types (HPV16, 31, 33, 52, 58, 51, 53, 66, 18, 39, 59, $68,6,44)$ in Shanghai women with cervical lesions. This comprehensive analysis will help us understand the clinical and biological role of sequence variation.

\section{Materials and methods}

\section{Study population}

In total, $262 \mathrm{HPV}$-positive patients (mean age 38.34 \pm 10.52 years, $21-78$ ) with histopathologically confirmed cervical lesions, including 92 nonneoplastic, 69 low-grade squamous intraepithelial lesion (LSIL) and 101 high-grade squamous intraepithelial lesion (HSIL), were recruited from the Cervical Disease Centre at the Shanghai First Maternity and Infant Hospital, Tongji University School of Medicine in Shanghai, China. Histopathological findings are divided into certain groups as nonneoplastic (chronic cervicitis and inflammation-related regenerative changes), LSIL (CIN I/mild dysplasia), HSIL (CIN II and $\mathrm{CIN} \mathrm{III/moderate} \mathrm{and} \mathrm{severe} \mathrm{dysplasia)} \mathrm{and} \mathrm{invasive} \mathrm{car-}$ cinoma. CIN I refers to mildly atypical cellular changes in the lower third of the epithelium, CIN II refers to moderately atypical cellular changes confined to the basal twothirds of the epithelium (formerly called moderate dysplasia) with preservation of epithelial maturation. CIN III refers to severely atypical cellular changes encompassing greater than two-thirds of the epithelial thickness and includes full-thickness lesions (previous terms were severe dysplasia or carcinoma in situ).

The criteria for the inclusion of patients enrolled into their current study: HPV single infection; Histopathologically confirmed by Colposcopy biopsy. The exclusion: Coinfected with different HPV types; Not histopathologically confirmed; the patients with vaginitis or other bacterial/ virus infection.

\section{Genomic DNA isolation and HPV typing}

DNA from exfoliated cervical cells was extracted using the TIANamp Genomic DNA Kit (No: 3304-9) according to the manufacturer's instructions. HPV genotyping was conducted using an HPV GenoArray Test Kit (HybriBio Ltd).

\section{Amplification and sequencing}

After HPV testing, the remaining DNA samples were stored at $-80^{\circ} \mathrm{C}$ and used to amplify $E 6$ and $E 7$ using specific primers (Table 1 ). Subsequently, PCR products excised from $1.5 \%$ agarose gel were sequenced bidirectionally by SAIYIN Gene Biotechnology Company, Shanghai, China.

\section{Phylogenetic tree analysis and sequence analysis}

The neighbour-joining phylogenetic tree of the HPVs was constructed by MEGA 7.0 using the maximum composite likelihood estimate [12]. To construct distinct phylogenetic branches, the reference HPV sequences were obtained from the GenBank database. The phylogenetic trees were visualised in FigTree v1.4.3 and online Evolview [13, 14].

The sequences were subsequently analysed by NCBI Blast, and all unique sequences were compared pairwise using the ClustalW tool of MEGA 7.0. The nucleotide positions of HPV were numbered on the basis of the reference sequence KU298876.1 (HPV6), NC_001526 (HPV16), NC_ 001526 (HPV18), J04353.1 (HPV31), M12732.1 (HPV33), M62849.1 (HPV39), U31788.1 (HPV44), KU298901.1 (HPV51), NC_001592.1 (HPV52), GQ472849.1 (HPV53), 
Table 1 Primers used for the molecular characterization of fourteen human papillomavirus E6 and E7 genes

\begin{tabular}{|c|c|c|c|c|c|c|c|}
\hline HPV genotype & Reference sequence ID & Gene & Direction & Sequence $5^{\prime}-3^{\prime}$ & Primer position & Product size, bp & $\begin{array}{l}\text { Annealing } \\
\text { Temperature, }{ }^{\circ} \mathrm{C}\end{array}$ \\
\hline \multirow[t]{2}{*}{6} & KU298876.1 & $E 6, E 7$ & Forward & AGGGACCGAAAACGGTTCAA & 32 & 1079 & 58 \\
\hline & & & Reverse & CTAACATATGGACTACCTAAAT & 1110 & & \\
\hline \multirow[t]{4}{*}{16} & NC_001526 & E6 & Forward & ACCGTTTGGGTTACACATTTAC & 6996 & 700 & 60 \\
\hline & & & Reverse & CTGTCATTTAATTGCTCATAACAGTAGA & 7695 & & \\
\hline & & E7 & Forward & CATTAGAACAGCAATACAACAAACC & 7405 & 579 & 60 \\
\hline & & & Reverse & TCCACTACAGCCTCTACATAAAACC & 7983 & & \\
\hline \multirow[t]{2}{*}{18} & NC_001526 & $E 6, E 7$ & Forward & CATGTCCAACATTCTGTCTACCC & 7751 & 1064 & 58 \\
\hline & & & Reverse & TTACAACCCGTGCCCTCC & 957 & & \\
\hline \multirow[t]{2}{*}{31} & J04353.1 & $E 6, E 7$ & Forward & AGTAGGGAGTGACCGAAAGTGG & 27 & 959 & 58 \\
\hline & & & Reverse & CACTACTGTCTTCATTITCGTCCTC & 985 & & \\
\hline \multirow[t]{2}{*}{33} & M12732.1 & $E 6, E 7$ & Forward & AACTATGCCTTGTAAAAGTGAGTCAC & 7813 & 1116 & 58 \\
\hline & & & Reverse & TAAATCCGTGCCACTGTCATC & 1015 & & \\
\hline \multirow[t]{2}{*}{39} & M62849.1 & $E 6, E 7$ & Forward & AAGGGAGTAACCGAAAACGG & 34 & 1096 & 58 \\
\hline & & & Reverse & CCTGTGCTGTCTCACGCTCT & 1129 & & \\
\hline \multirow[t]{2}{*}{44} & U31788.1 & $E 6, E 7$ & Forward & ATCGGTTGACACACACCCTG & 7796 & 1083 & 58 \\
\hline & & & Reverse & CATCCGCCTCCTGTCGTTTAACAA & 1045 & & \\
\hline \multirow[t]{2}{*}{51} & KU298901.1 & $E 6, E 7$ & Forward & ACTAGGGTGTAACCGAAAAGGG & 17 & 965 & 58 \\
\hline & & & Reverse & TCATCCTCATCATCCGAAACAT & 981 & & \\
\hline \multirow[t]{4}{*}{52} & NC_001592.1 & E6 & Forward & ACCGTACCCACAACCACTITT & 7929 & 738 & 58 \\
\hline & & & Reverse & TTGTGGCTTGTTCTGCTTGTC & 706 & & \\
\hline & & E7 & Forward & AACGCCATTATGTCCTGAAGAA & 422 & 554 & 58 \\
\hline & & & Reverse & CATCCTCGTCCTCTGAAATGTTAT & 975 & & \\
\hline \multirow[t]{2}{*}{53} & GQ472849.1 & $E 6, E 7$ & Forward & AGACAGGGAGTAACCGAAATAGG & 24 & 988 & 58 \\
\hline & & & Reverse & GCTITCCTCGTCTGTTICATCTT & 1011 & & \\
\hline \multirow[t]{4}{*}{58} & D90400 & E6 & Forward & CGTITGGGTCACATTGTTCA & 7782 & 702 & 58 \\
\hline & & & Reverse & CATAATTGCTCATAGCAGAATAGGTC & 659 & & \\
\hline & & E7 & Forward & TTCGCTATATGGAGACACATTAGAA & 352 & 613 & 58 \\
\hline & & & Reverse & TTCTTCGTTCTATTACCGCTTCTA & 964 & & \\
\hline \multirow[t]{2}{*}{59} & X77858.1 & $E 6, E 7$ & Forward & AAGCAACCGAAAAAGGTCGG & 7805 & 1128 & 58 \\
\hline & & & Reverse & TGTGGTATCATCAATAAAATCTACC & 1036 & & \\
\hline \multirow[t]{2}{*}{66} & U31794.1 & $E 6, E 7$ & Forward & TTGGGAGTAACCGAAATGGG & 27 & 992 & 58 \\
\hline & & & Reverse & САTTCTCСТCСТCGCTTTCAT & 1018 & & \\
\hline \multirow[t]{2}{*}{68} & DQ080079 & $E 6, E 7$ & Forward & CCGAAAAAGGTTGGGCACAC & 7682 & 1098 & 58 \\
\hline & & & Reverse & TGAACCTGTATCTGTTGCGTT & 958 & & \\
\hline
\end{tabular}

HPV Human papillomavirus

D90400 (HPV58), X77858.1 (HPV59), U31794.1 (HPV66), and DQ080079 (HPV68).

\section{Statistical analysis}

Fisher's exact test was chosen for statistical analysis. $P<$ 0.05 was used as the threshold to indicate statistical significance. All the $P$ values in the present study were two-sided. The power calculation was performed by G* power software [15].

\section{Results}

In this study, total DNA was extracted from exfoliated cervical cell samples from $262 \mathrm{HPV}$-positive patients. In total, 233 E6 and 212 E7 sequences were successfully amplified by PCR. Based on the reference sequences, we confirmed that these sequences were divided into 14 types of HPV $(16,31,33,52,58,51,53,66,18,39$, $59,68,6,44)$ and 5 species groups (alpha-5, alpha-6, alpha-7, alpha-9, alpha-10) using phylogenetic tree 
analysis, where alpha-10 was a low-risk (LR) clade (Fig. 1 and Fig. 2).

Table 2 shows the distribution of the sublineagespecific infections for individual types in cervicitis, LSIL and HSIL groups. The incidence of HSIL was significantly increased in patients infected with alpha-9 HPV compared with other species $(P<0.0001)$, especially HPV16 $(P<$ $0.0001)$. There was no statistically significant difference in the severity of CIN for all types of lineages. For HPV16, 37.5\% HPV16 A1-3 sub-lineage caused HSIL, as well as 75.9\% A4. Among 54 determinable samples of HPV 52, the $\mathrm{A}, \mathrm{B}$ and $\mathrm{C}$ variants were found in 1 (1.85\%), 52 (96.3\%) and 1 (1.85\%) samples, respectively, and lineage B was the most common. Among 45 determinable samples of HPV 58, sublineages A1, A2 and A3 variants were found in 57.8, 22.2 and $17.8 \%$ of all HPV58 samples,

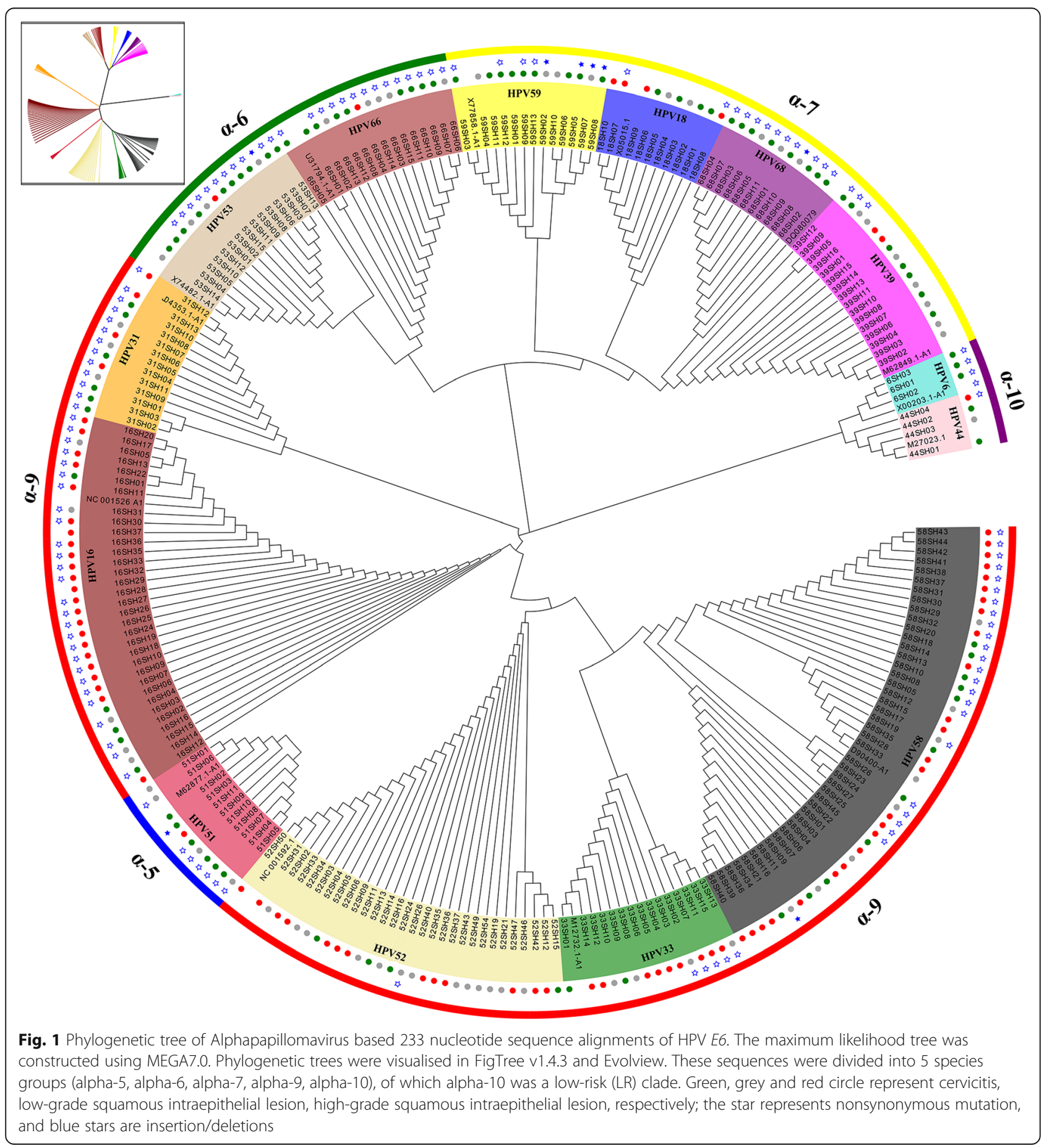




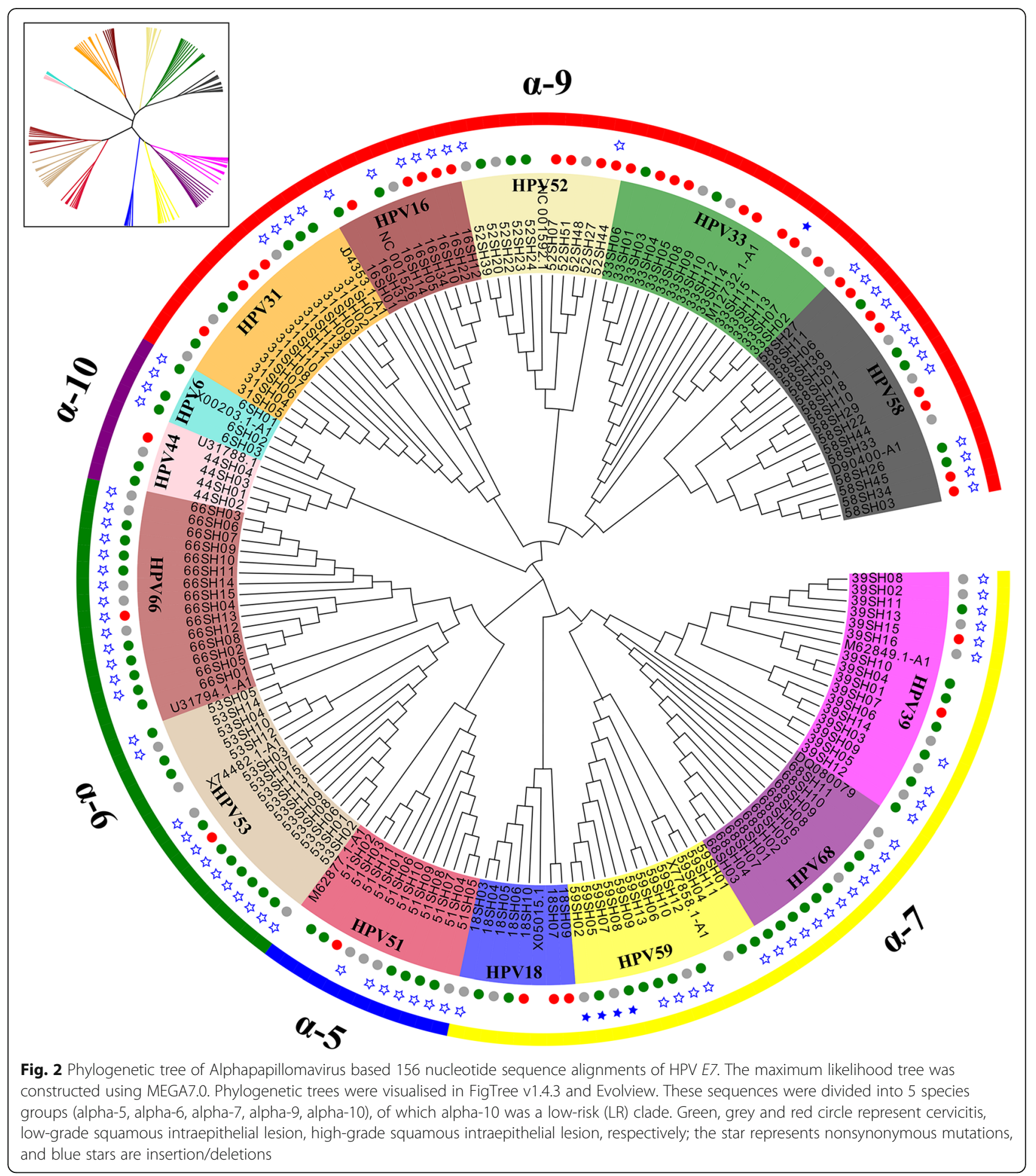

respectively. The nonprototype-like variant (sublineage B1) of HPV58 was rare in our study. A2 $(69.23 \%, 9 / 13)$ and A1 $(66.67 \%, 10 / 15)$ were common sublineages for HPV31 and HPV33, respectively.

Interestingly, we observed that one variant represented four out of 13 HPV59-positive samples that appeared to form a new candidate, sublineage B1-2 (Fig. 3a). A 9- base sequence (AGTGAAACT) was inserted after position 519 of the E6 sequence, and 9 inserted bases were translated into 3 amino acids SET (Fig. $3 \mathrm{~b}$ and c). These diagnostic SNPs were unique to the B1-2 sublineage.

Nonsynonymous mutations for the E6 and $E 7$ genes within all types of HPV were evaluated. The A burden test was used to determine if the variant distribution was 
Table 2 Distribution of lineage-specific human papillomavirus infections in samples from Shanghai

\begin{tabular}{|c|c|c|c|c|c|c|c|c|}
\hline \multirow{2}{*}{$\overline{\text { Genus }}$} & \multirow[b]{2}{*}{ Type } & \multirow{2}{*}{$\begin{array}{l}\text { Age }^{\#} \\
(\text { Mean } \pm S D)\end{array}$} & \multirow{2}{*}{$\begin{array}{l}\text { Lineage or } \\
\text { sublineage }\end{array}$} & \multirow{2}{*}{$\begin{array}{l}\text { Women } \\
\mathrm{N}\end{array}$} & \multicolumn{2}{|c|}{ pathologic diagnosis } & \multirow[b]{2}{*}{ HSIL } & \multirow[b]{2}{*}{$P^{*}$ Value } \\
\hline & & & & & IF & LSIL & & \\
\hline \multirow[t]{16}{*}{$a-9$} & & & & 164 & 34 & 39 & 91 & $<0.0001^{a}$ \\
\hline & 16 & $34.88 \pm 6.15$ & A1-3 & 8 & 3 & 2 & 3 & 0.083 \\
\hline & & $35.10 \pm 6.83$ & A4 & 29 & 2 & 5 & 22 & \\
\hline & 31 & $33.33 \pm 8.41$ & A2 & 9 & 3 & 2 & 4 & 0.108 \\
\hline & & & B2 & 1 & 0 & 1 & 0 & \\
\hline & & $31.67 \pm 5.51$ & $C 2$ & 3 & 3 & 0 & 0 & \\
\hline & 33 & $38.90 \pm 11.57$ & $\mathrm{~A} 1$ & 10 & 2 & 2 & 6 & 0.417 \\
\hline & & & $\mathrm{A} 2$ & 1 & 0 & 1 & 0 & \\
\hline & & $39.75 \pm 8.18$ & A3 & 4 & 0 & 1 & 3 & \\
\hline & 52 & & A & 1 & 0 & 0 & 1 & 1 \\
\hline & & $38.48 \pm 11.83$ & B & 52 & 10 & 17 & 25 & \\
\hline & & & C & 1 & 0 & 0 & 1 & \\
\hline & 58 & $40.19 \pm 9.55$ & $\mathrm{~A} 1$ & 26 & 7 & 4 & 15 & 0.862 \\
\hline & & $40.30 \pm 7.54$ & $\mathrm{~A} 2$ & 10 & 1 & 3 & 6 & \\
\hline & & $44.25 \pm 14.44$ & A3 & 8 & 3 & 1 & 4 & \\
\hline & & & B1 & 1 & 0 & 0 & 1 & \\
\hline \multirow[t]{4}{*}{$a-5$} & & & & 11 & 6 & 4 & 1 & \\
\hline & 51 & & $\mathrm{~A} 1$ & 1 & 0 & 1 & 0 & 0.532 \\
\hline & & $36.50 \pm 7.94$ & $\mathrm{~A} 2$ & 4 & 2 & 1 & 1 & \\
\hline & & $39.83 \pm 14.68$ & A4 & 6 & 4 & 2 & 0 & \\
\hline \multirow[t]{9}{*}{$a-6$} & & & & 30 & 19 & 9 & 1 & \\
\hline & 53 & $34.00 \pm 5.66$ & $\mathrm{~A} 1$ & 2 & 1 & 1 & 0 & 0.588 \\
\hline & & $42.50 \pm 12.02$ & B1 & 2 & 1 & 1 & 0 & \\
\hline & & $33.33 \pm 10.41$ & $\mathrm{C} 1$ & 3 & 2 & 1 & 0 & \\
\hline & & $31.00 \pm 7.07$ & D1 & 2 & 1 & 1 & 0 & \\
\hline & & $36.00 \pm 13.36$ & D3 & 6 & 5 & 0 & 1 & \\
\hline & 66 & & $\mathrm{~A} 1$ & 1 & 1 & 0 & 0 & 0.552 \\
\hline & & $45.17 \pm 13.53$ & B1 & 6 & 4 & 1 & 1 & \\
\hline & & $42.50 \pm 13.18$ & B2 & 8 & 4 & 4 & 0 & \\
\hline \multirow[t]{11}{*}{$a-7$} & & & & 50 & 28 & 16 & 6 & \\
\hline & 18 & $34.50 \pm 10.42$ & $\mathrm{~A} 1$ & 10 & 4 & 2 & 4 & 0.4 \\
\hline & 39 & $39.08 \pm 10.49$ & $\mathrm{~A} 1$ & 13 & 5 & 6 & 2 & 1 \\
\hline & & $43.00 \pm 22.63$ & $A 2$ & 2 & 1 & 1 & 0 & \\
\hline & & & B1 & 1 & 1 & 0 & 0 & \\
\hline & 5 & $33.50 \pm 8.96$ & $\mathrm{~A} 1$ & 4 & 3 & 1 & 0 & 0.664 \\
\hline & & $36.00 \pm 2.65$ & A3 & 3 & 3 & 0 & 0 & \\
\hline & & $36.50 \pm 6.36$ & B1 & 2 & 1 & 1 & 0 & \\
\hline & & $51.25 \pm 5.00$ & B1-2 & 4 & 2 & 2 & 0 & \\
\hline & 68 & $45.00 \pm 10.90$ & $\mathrm{C} 1$ & 9 & 6 & 3 & 0 & 1 \\
\hline & & $35.00 \pm 8.49$ & $C 2$ & 2 & 2 & 0 & 0 & \\
\hline \multirow[t]{3}{*}{$a-10$} & & & & 7 & 5 & 1 & 1 & \\
\hline & 6 & $34.33 \pm 12.06$ & B1 & 3 & 3 & 0 & 0 & \\
\hline & 44 & $32.50 \pm 4.04$ & & 4 & 2 & 1 & 1 & \\
\hline Total & & & & 262 & 92 & 69 & 101 & $<0.0001^{b}$ \\
\hline
\end{tabular}

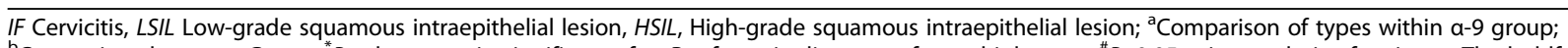
${ }^{\mathrm{b}}$ Comparison between Genus; ${ }^{*} P$ values remain significant after Bonferroni adjustment for multiple tests. ${ }^{\#} P<0.05$ using analysis of variance. The boldface entries indicate the distribution of $a-5, a-6, a-7, a-9$ and $a-10$ HPV infection in different populations (IF, LSIL and HSIL group) 


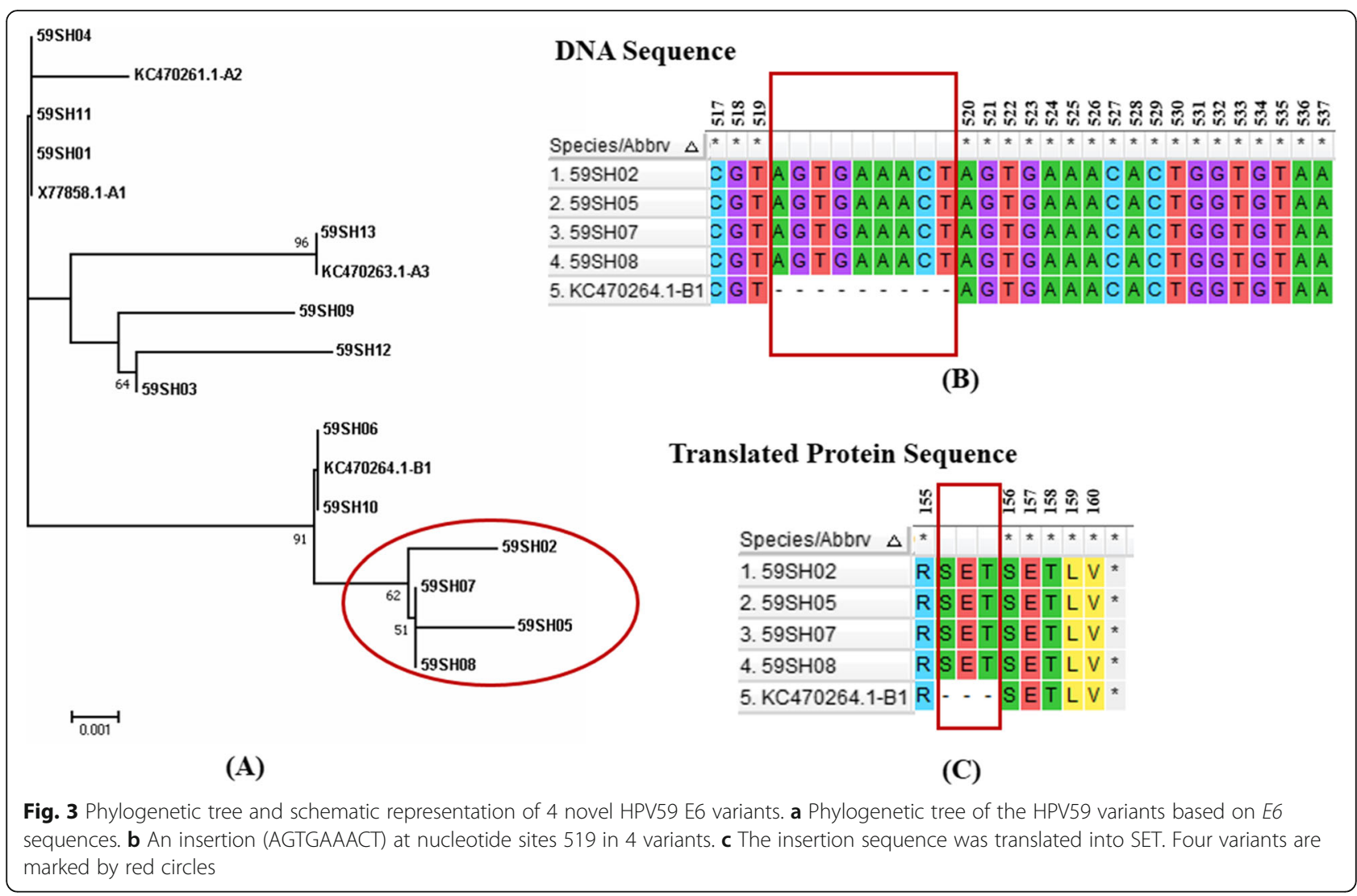

different between the IF, LSIL and HSIL groups by viral region (Table 3, Fig. 1, and Fig. 2). Despite nearly equal numbers of E6 and E7 sequences among three groups (IF, 159; LSIL, 121; HSIL, 165), the IF group overall had a significantly higher number of variants compared to the LSIL and HSIL groups $\left(P=3.83 \times 10^{-4}\right)$. Strikingly, the $E 7$ gene had significantly fewer nonsynonymous variants in the HSIL compared to LSIL and IF groups $(P=$ $\left.3.17 \times 10^{-4}\right)$.

Moreover, we confirmed that the incidence of HSIL in patients infected with the alpha-9 HPV group was significantly increased compared with the other groups $(P<0.0001)$. We then further analysed nonsynonymous mutations of the alpha-9 HPV (HPV16, 31, 33, 52, 58) $E 6$ and $E 7$ genes in the HSIL case and control groups
(Table 4). In the case group, 13 variations were observed in the $E 6$ gene, and 19 mutations were observed in the $E 7$ gene. In the control group, 17 and 14 variations were found in the $E 6$ and $E 7$ genes, respectively. For HPV16, the distribution of T7220G (D32E) variation in E6 and A7689G (N29S) in E7 showed a different trend between the case group and control group $(P=0.036$ and 0.022$)$ (Table 4), power (1- $\beta$ ) 0.562 and 0.629. For HPV58, A388C $(K 93 \mathrm{~N})$ variation can significantly reduce the risk of HSIL and was a protective factor $(P=0.015)$, power $(1-\beta)$ 0.624. In the remaining three types of alpha$9 \mathrm{HPV}$, no significant differences in the distribution of other variations between the case group and the control group were found. In addition, we performed covariation analysis of five HPVs $E 6$ and $E 7$ genes in the $\alpha$ -

Table 3 Rare variant burden analysis for nonsynonymous variants within all types of HPV for the cervicitis, LSIL and HSIL groups

\begin{tabular}{lllllllllll}
\hline & \multicolumn{3}{c}{} & N Controls & \multicolumn{3}{c}{ N LSIL } & \multicolumn{3}{c}{ N HSIL } \\
Viral & Number & with & \% of & Number & with & \% of & Number & with & \% of \\
Gene & IF & Variants & Controls & LSIL & Variants & Controls & HSIL & Variants & Controls & $P$ Value \\
\hline E6 & 86 & 55 & 64.0 & 63 & 32 & 50.8 & 84 & 45 & 53.6 & 0.215 \\
E7 & 73 & 53 & 72.6 & 58 & 31 & 53.4 & 81 & 32 & 39.5 & $3.17 \times 10^{-4^{*}}$ \\
Total & 159 & 108 & 67.9 & 121 & 63 & 52.1 & 165 & 77 & 46.7 & $3.83 \times 10^{-4^{*}}$ \\
\hline
\end{tabular}

HPV Human papillomavirus; IF cervicitis; LSIL low-grade squamous intraepithelial lesion; HSIL high-grade squamous intraepithelial lesion; ${ }^{*}$ values remain significant after Bonferroni adjustment for multiple tests 
Table 4 HPV E6/E7 gene variations and amino acid substitutions in the case and control groups

\begin{tabular}{|c|c|c|c|c|c|c|c|}
\hline \multirow[t]{2}{*}{ HPV } & \multirow{2}{*}{$\begin{array}{l}\text { Genome } \\
\text { position }^{\mathrm{a}}\end{array}$} & \multirow{2}{*}{$\begin{array}{l}\text { Amino } \\
\text { acid }^{a}\end{array}$} & \multicolumn{2}{|l|}{ Case $^{b}$} & \multicolumn{2}{|l|}{ Control $^{c}$} & \multirow{2}{*}{$\begin{array}{l}P \\
\text { value }\end{array}$} \\
\hline & & & Mutation & Frequency $(\%)$ & Mutation & Frequency (\%) & \\
\hline \multirow{6}{*}{$\begin{array}{l}\text { HPV16 } \\
\text { E6 case }(n=23) \\
\text { control }(n=10)\end{array}$} & T7179G & L19V & 1 & 4.3 & 0 & 0.0 & 1.000 \\
\hline & T7220G & D32E & 20 & 87.0 & 5 & 50.0 & 0.036 \\
\hline & C7377T & $\mathrm{H} 85 \mathrm{Y}$ & 0 & 0.0 & 1 & 10.0 & 0.303 \\
\hline & G7384C & C87S & 2 & 8.7 & 0 & 0.0 & 1.000 \\
\hline & A7404T & T94S & 3 & 13.0 & 1 & 10.0 & 1.000 \\
\hline & A7484C & E120D & 1 & 4.3 & 1 & 10.0 & 0.521 \\
\hline \multirow{3}{*}{$\begin{array}{l}\text { E7 case }(n=21) \\
\text { control }(n=10)\end{array}$} & A7688C & $\mathrm{N} 29 \mathrm{H}$ & 0 & 0.0 & 1 & 10.0 & 0.323 \\
\hline & A7689G & N29S & 19 & 90.5 & 5 & 50.0 & 0.022 \\
\hline & C7832T & $\mathrm{R} 77 \mathrm{C}$ & 1 & 4.8 & 1 & 10.0 & 1.000 \\
\hline \multirow{4}{*}{$\begin{array}{l}\text { HPV31 } \\
\text { E6 case }(n=4) \\
\text { control }(n=9)\end{array}$} & $\mathrm{C} 285 \mathrm{~T}$ & H6OY & 0 & 0.0 & 3 & 33.3 & 0.497 \\
\hline & A297G & T64A & 0 & 0.0 & 1 & 11.1 & 1.000 \\
\hline & A475G & K123R & 0 & 0.0 & 1 & 11.1 & 1.000 \\
\hline & С520T & A138V & 0 & 0.0 & 4 & 44.4 & 0.228 \\
\hline \multirow{3}{*}{$\begin{array}{l}\text { E7 case }(n=4) \\
\text { control }(n=9)\end{array}$} & C626T & $\mathrm{H} 23 \mathrm{~K}$ & 4 & 100.0 & 6 & 66.7 & 0.497 \\
\hline & G695A & E46K & 0 & 0.0 & 4 & 44.4 & 0.228 \\
\hline & A743G & $\mathrm{K} 62 \mathrm{E}$ & 4 & 100.0 & 9 & 100.0 & - \\
\hline \multirow{4}{*}{$\begin{array}{l}\text { HPV33 } \\
\text { E6 case }(n=9) \\
\text { control }(n=6)\end{array}$} & A213C & $\mathrm{K} 35 \mathrm{~N}$ & 3 & 33.3 & 2 & 33.3 & 1.000 \\
\hline & A364C & $\mathrm{N} 86 \mathrm{H}$ & 3 & 33.3 & 2 & 33.3 & 1.000 \\
\hline & A387C & K93N & 3 & 33.3 & 1 & 16.7 & 0.604 \\
\hline & A446G & Q113R & 3 & 33.3 & 1 & 16.7 & 0.604 \\
\hline \multirow{3}{*}{$\begin{array}{l}\text { E7 case }(n=9) \\
\text { control }(n=6)\end{array}$} & A834G & N88D & 1 & 11.1 & 0 & 0.0 & 1.000 \\
\hline & C850A & T93N & 1 & 11.1 & 0 & 0.0 & 1.000 \\
\hline & A862T & Q97L & 3 & 33.3 & 2 & 33.3 & 1.000 \\
\hline $\begin{array}{l}\text { HPV52 } \\
\text { E6 case }(n=13) \\
\text { control }(n=17)\end{array}$ & G108C & E3Q & 0 & 0.0 & 1 & 5.9 & 1.000 \\
\hline \multirow{7}{*}{$\begin{array}{l}\text { E7 case }(n=27) \\
\text { control }(n=26)\end{array}$} & C624G & $\mathrm{C} 24 \mathrm{~W}$ & 0 & 0.0 & 1 & 3.8 & 0.491 \\
\hline & C662T & T371 & 1 & 3.7 & 0 & 0.0 & 1.000 \\
\hline & G707A & S52D & 1 & 3.7 & 0 & 0.0 & 1.000 \\
\hline & $\mathrm{T} 727 \mathrm{G}$ & Y59D & 1 & 3.7 & 0 & 0.0 & 1.000 \\
\hline & C733T & H61Y & 1 & 3.7 & 0 & 0.0 & 1.000 \\
\hline & $\mathrm{G} 742 \mathrm{~A}$ & D64N & 1 & 3.7 & 0 & 0.0 & 1.000 \\
\hline & T848G & L99R & 1 & 3.7 & 0 & 0.0 & 1.000 \\
\hline \multirow{5}{*}{$\begin{array}{l}\text { HPV58 } \\
\text { E6 case }(n=25) \\
\text { control }(n=18)\end{array}$} & G203C & E32Q & 3 & 12.0 & 1 & 5.6 & 0.628 \\
\hline & $\mathrm{C} 228 \mathrm{~T}$ & $\mathrm{~S} 40 \mathrm{~F}$ & 1 & 4.0 & 0 & 0.0 & 1.000 \\
\hline & C367A & D86E & 2 & 8.0 & 2 & 11.1 & 1.000 \\
\hline & A388C & K93N & 1 & 4.0 & 6 & 33.3 & 0.015 \\
\hline & A544T & K145S & 0 & 0.0 & 1 & 5.6 & 0.419 \\
\hline \multirow{8}{*}{$\begin{array}{l}\text { E7 case }(n=12) \\
\text { control }(n=9)\end{array}$} & C632T & T201 & 3 & 25.0 & 3 & 33.3 & 1.000 \\
\hline & G694A & G41R & 3 & 25.0 & 2 & 22.2 & 1.000 \\
\hline & C755A & T61N & 0 & 0.0 & 1 & 11.1 & 0.429 \\
\hline & $\mathrm{G} 760 \mathrm{~A}$ & G63S & 4 & 33.3 & 2 & 22.2 & 0.659 \\
\hline & $\mathrm{G} 761 \mathrm{~A}$ & G63D & 3 & 25.0 & 2 & 22.2 & 1.000 \\
\hline & A793G & $\mathrm{T} 74 \mathrm{~A}$ & 1 & 8.3 & 0 & 0.0 & 1.000 \\
\hline & C801A & D76E & 1 & 8.3 & 0 & 0.0 & 1.000 \\
\hline & T803C & V77A & 0 & 0.0 & 3 & 33.3 & 0.063 \\
\hline
\end{tabular}


9 group. But there was no significant correlation between E6 and E7 covariation and cervical lesions (Additional file 1: Table S1).

\section{Discussion}

Persistent infection with HPV is the most important risk factor for cervical cancer [16]. According to their oncogenic potential, HPV types are divided into high-risk HPV types $(16,18,31,33,35,39,45,51,52$, and 58$)$ associated with cervical cancers, and low-risk types $(6,11,40,42,43$, 44, and 54) associated with genital warts [17]. The E6 and E7 oncoproteins of HPV contribute to oncogenesis by associating with the tumour suppressor proteins p53 and $\mathrm{pRb}$, respectively [18]. In this report, we describe the E6 and E7 genes of 14 conventional HPV species (HPV16, 31, $33,52,58,51,53,66,18,39,59,68,6,44)$ in Shanghai women with cervical lesions. This work provides basic information and reference variant sequences for future investigation of viral-host evolution and viral pathogenesis.

In this study, the $\alpha-9$ (HPV16, 31, 33, 52, 58), $\alpha-5$ (HPV51), $\alpha-6$ (HPV53, 66), $\alpha-7$ (HPV18, 39, 59, 68) and $\alpha-10$ (HPV6, 44) were were detected and analyzed. $79.26 \%$ of $\alpha-9$ HPV infection caused CIN confirmed histopathologically, 55.49\% of which were HSIL. HPV16 A4, HPV31 A2, HPV33 A1, HPV52 B and HPV58 A1 were the most common sublineages in the $\alpha-9 \mathrm{HPV}$ group. In China, the A1-A3 sublineage of HPV16 was predominant in northeast China [19], and A4 was common in central and south China [20, 21]. Globally, the risk of cervical cancer caused by the A3, A4 and D sublineages was significantly higher compared with HPV16 A1 [22]. In our study, HPV 31/33/52/58 had variant lineages similar to those reported by previous studies, and sublineages associated with $\mathrm{CIN}$ and/or cervical cancer were HPV52 C and HPV33 A1 [8, 23-26]. We should improve the screening of cervical cancer based on HPV pathogenic sub-lineages in different regions. This also reduces the rate of colposcopy biopsy, which can reduce the burden on patients and reduce the waste of medical resources. Simple infections of HPV16 carcinogenic subtypes or low-grade lesions caused by them should be intervened as early as possible rather than just follow-up. However, the sample size should be expanded to further confirm our research results.

The genome variations in humans and HPV may influence any stage of HPV infection by inducing cervical cancer [27]. For E6, the T7220G (D32E) variation in HPV16 E6 was a risk factor that increased the incidence of HSIL, whereas A388C(K93 N) variation in HPV58 E6 significantly reduced the risk of HSIL. Previous studies have shown that the susceptibility to cervical disease is increased by the specific protein interaction HPV16 E6 (L83 V)-p53 (Arg-72, [28]. Moreover, the gene variant
T350G of HPV-16 was found to display more efficient degradation of Bax and binding to the E6 binding protein [29]. We found that E7 was highly conserved in the HSIL group compared to the <HSIL group, and A7689G (N29S) in E7 significantly increased the risk of HSIL. While the HPV16 A4 sublineage $(P<0.0001)$ and HPV16 E7 29S $(P=0.0002)$ rarely occurred in cancer patients compared to women with cervicitis in Vietnam [30]. HPV16 E7 S63F was significantly different between the case and control groups $\left(P=4.861 \times 10^{-10}\right)$ in a Han Chinese population [31]. The T20I/G63S substitutions in HPV16 A3 E7 significantly increased the risk for HSIL in Taizhou area, China [32]. In one word, HPV sublineage and variation dispersal was population-specific, and we should develop different screening and treatment schemes according to the distribution of HPV variation in different regions. Due to the limitation of sample capacity, we should increase the sample size to confirm the role and mechanism of these mutations in the development of cervical cancer in Shanghai area or south China.

In current study, the E7 gene had significantly fewer nonsynonymous variants in the HSIL compared to LSIL and IF groups $(P=3.17 \times 10-4)$. Lisa Mirabello et al. confirmed hypovariation in that E7 had significantly fewer, rare non-silent genetic variants in cancers $(P=$ $6.13 \times 10^{-5}$ ) compared to E6 [33]. Previous studies have reported that the HPV16 E7 protein leading to cervical cancer is virtually invariant, and E7 displayed a fully conserved sequence [34, 35]. In summary, E7 variation greatly decreases the risk of CIN and invasive cancer.

\section{Conclusions}

In this study, we focused on the phylogeny and polymorphism of $14 \mathrm{HPV}$ variants based on the E6 and E7 genes. In addition, we also found that the $E 7$ gene lacked significant genetic variation in $\mathrm{CIN}$, and which was strict conservation in the HSIL. This comprehensive analysis will help us understand the clinical and biological effects of sequence changes and provide preventative/therapeutic interventions for HPV-related CIN and cervical cancer.

\section{Supplementary information}

Supplementary information accompanies this paper at https://doi.org/10. 1186/s13027-019-0250-9.

Additional file 1 Table S1. Co-variations analysis of a-9 HPV E6 and E7 gene in the case and control groups.

\section{Abbreviations}

CIN: Cervical intraepithelial neoplasia; HPV: Human papillomavirus; HSIL: High-grade squamous intraepithelial lesion; LSIL: Low-grade squamous intraepithelial lesion

Acknowledgements

We are thankful to the American Journal Experts for English language editing. 


\section{Authors' contributions}

JWZ, YTR, QZY, ML and JHG conceived the study. FL and LFH directed the study. JHG and QZ contributed to the collection of samples and clinical information. YTR and ML performed PCR. JWZ performed the statistical analysis. JWZ, ML and TLZ performed the phylogenetic tree analysis and sequence analysis. JWZ, YTR, QZY, ML, JHG and TLZ wrote the manuscript with the assistance and final approval of all authors. LFH and FL corrected the manuscript. All the authors performed a critical revision of this manuscript. All authors read and approved the final manuscript.

\section{Funding}

This work was supported by the National Natural Science Foundation of China (Grant NO. 81771529, 81572546, 81972422), the Shanghai Science and Technology Development Foundation (Grant NO. 17441902500), the Fundamental Research Funds for the Central Universities (NO.22120190241, 22120190214), and the Shanghai Hospital Development Center Foundation (Grant NO. 16CR3089B).

\section{Availability of data and materials}

The datasets used and/or analysed during the current study are available from the corresponding author on reasonable request.

\section{Ethics approval and consent to participate}

This study was approval by the Institutional Ethics Committee of Shanghai First Maternity and Infant Hospital, Tongji University School of Medicine (No: KS 1714). Informed consent was obtained from the studied patients.

\section{Consent for publication}

Informed consent Informed consent was obtained from all individual participants included in the study.

\section{Competing interests}

The authors declare that they have no competing interests.

\section{Author details}

'Department of Obstetrics and Gynecology, East Hospital, Tongji University School of Medicine, 150 Jimo Rd, Shanghai 200120, People's Republic of China. ${ }^{2}$ Department of Gynecology, Shanghai First Maternity and Infant Hospital, Tongji University School of Medicine, Shanghai 201204, China. ${ }^{3}$ School of Physics HH Wills Physics Laboratory, University of Bristol, Bristol, UK.

\section{Received: 12 July 2019 Accepted: 21 October 2019}

\section{Published online: 21 November 2019}

\section{References}

1. Sichero L, El-Zein M, Nunes EM, Ferreira S, Franco EL, Villa LL, Ludwig-McGill Cohort S. Cervical infection with cutaneous Beta and Mucosal alpha papillomaviruses. Cancer Epidemiol Biomark Prev. 2017:26:1312-20.

2. Chen Z, Schiffman M, Herrero R, DeSalle R, Anastos K, Segondy M, Sahasrabuddhe W, Gravitt PE, Hsing AW, Chan PKS, Burk RD. Classification and evolution of human papillomavirus genome variants: Alpha-5 (HPV26, 51, 69, 82), Alpha-6 (HPV30, 53, 56, 66), Alpha-11 (HPV34, 73), Alpha-13 (HPV54) and Alpha-3 (HPV61). Virology. 2018;516:86-101.

3. de Martel C, Plummer M, Vignat J, Franceschi S. Worldwide burden of cancer attributable to HPV by site, country and HPV type. Int I Cancer. 2017; 141:664-70.

4. Schiffman M, Doorbar J, Wentzensen N, de Sanjose S, Fakhry C, Monk BJ, Stanley MA, Franceschi S. Carcinogenic human papillomavirus infection. Nat Rev Dis Primers. 2016;2:16086.

5. Cornet I, Gheit T, lannacone MR, Vignat J, Sylla BS, Del Mistro A, Franceschi S, Tommasino M, Clifford GM. HPV16 genetic variation and the development of cervical cancer worldwide. Br J Cancer. 2013;108:240-4.

6. Freitas LB, Chen Z, Muqui EF, Boldrini NA, Miranda AE, Spano LC, Burk RD. Human papillomavirus 16 non-European variants are preferentially associated with high-grade cervical lesions. PLoS One. 2014;9:e100746.

7. Mirabello L, Yeager M, Cullen M, Boland JF, Chen Z, Wentzensen N, Zhang X, Yu K, Yang Q, Mitchell J, et al. HPV16 sublineage associations with histology-specific Cancer risk using HPV whole-genome sequences in 3200 women. J Natl Cancer Inst. 2016;108:djw100.

8. Chang YJ, Chen HC, Lee BH, You SL, Lin CY, Pan MH, Chou YC, Hsieh CY, Chen YM, Cheng YJ, et al. Unique variants of human papillomavirus genotypes 52 and 58 and risk of cervical neoplasia. Int J Cancer. 2011;129: 965-73.

9. Chen Z, Jing Y, Wen Q, Ding X, Wang T, Mu X, Chenzhang Y, Cao M. E6 and E7 gene polymorphisms in human papillomavirus Types-58 and 33 identified in Southwest China. PLoS One. 2017;12:e0171140.

10. Eckhardt M, Zhang W, Gross AM, Von Dollen J, Johnson JR, Franks-Skiba KE, Swaney DL, Johnson TL, Jang GM, Shah PS, et al. Multiple routes to Oncogenesis are promoted by the human papillomavirus-host protein network. Cancer Discov. 2018;8:1474-89.

11. Estevao D, Costa NR, Gil da Costa RM, Medeiros R. Hallmarks of HPV carcinogenesis: the role of E6, E7 and E5 oncoproteins in cellular malignancy. Biochim Biophys Acta Gene Regul Mech. 1862;2019:153-62.

12. Kumar S, Stecher G, Tamura K. MEGA7: molecular evolutionary genetics analysis version 7.0 for bigger datasets. Mol Biol Evol. 2016;33:1870-4.

13. Zhang H, Gao S, Lercher MJ, Hu S, Chen WH. EvolView, an online tool for visualizing, annotating and managing phylogenetic trees. Nucleic Acids Res. 2012:40:W569-72.

14. He Z, Zhang H, Gao S, Lercher MJ, Chen WH, Hu S. Evolview v2: an online visualization and management tool for customized and annotated phylogenetic trees. Nucleic Acids Res. 2016;44:W236-41.

15. Faul F, Erdfelder E, Lang AG, Buchner A. G* power 3: a flexible statistical power analysis program for the social, behavioral, and biomedical sciences. Behav Res Methods. 2007;39:175-91.

16. Bergengren L, Lillsunde-Larsson G, Helenius G, Karlsson MG. HPV-based screening for cervical cancer among women $55-59$ years of age. PLoS One. 2019;14:e0217108.

17. Mirbahari SG, Sadeghi M. The prevalence of genus alpha human papillomavirus in women with uterine cervical infection and/or inflammation in Western Iran. Mater Sociomed. 2018:30:113-7.

18. Gao R, Wu X, Huang Z, Wang B, Li F, Xu H, Ran L. Anti-tumor effect of aloe-emodin on cervical cancer cells was associated with human papillomavirus E6/E7 and glucose metabolism. Onco Targets Ther. 2019; 12:3713-21.

19. Zhe $X$, Xin H, Pan Z, Jin F, Zheng W, Li H, Li D, Cao D, Li Y, Zhang C, et al. Genetic variations in E6, E7 and the long control region of human papillomavirus type 16 among patients with cervical lesions in Xinjiang, China. Cancer Cell Int. 2019;19:65.

20. Cao M, Chenzhang Y, Ding X, Zhang Y, Jing Y, Chen Z. Genetic variability and lineage phylogeny of human papillomavirus type-16 and -53 based on the E6, E7, and L1 genes in Southwest China. Gene. 2016;592:49-59.

21. Liu Y, Pan Y, Gao W, Ke Y, Lu Z. Whole-genome analysis of human papillomavirus types 16, 18, and 58 isolated from cervical Precancer and Cancer samples in Chinese women. Sci Rep. 2017;7:263.

22. Clifford GM, Tenet V, Georges D, Alemany L, Pavon MA, Chen Z, Yeager M, Cullen M, Boland JF, Bass S, et al. Human papillomavirus 16 sub-lineage dispersal and cervical cancer risk worldwide: whole viral genome sequences from 7116 HPV16-positive women. Papillomavirus Res. 2019;7:67-74.

23. Zhang J, Zhang $S$, Wang $M$, Ding $X$, Wen $Q$, Chen Z, Cao M, Jing Y, Zhang $\mathrm{S}$. Genetic variability in E5, E6, E7 and L1 genes of human papillomavirus type 31. Mol Med Rep. 2018;17:5498-507.

24. Ferenczi A, Gyongyosi E, Szalmas A, Laszlo B, Konya J, Veress G. Phylogenetic and functional analysis of sequence variation of human papillomavirus type 31 E6 and E7 oncoproteins. Infect Genet Evol. 2016;43: 94-100

25. Tenjimbayashi $Y$, Onuki M, Hirose Y, Mori S, Ishii Y, Takeuchi T, Tasaka N, Satoh T, Morisada T, Iwata T, et al. Whole-genome analysis of human papillomavirus genotypes 52 and 58 isolated from Japanese women with cervical intraepithelial neoplasia and invasive cervical cancer. Infect Agent Cancer. 2017:12:44.

26. Chen AA, Heideman DA, Boon D, Chen Z, Burk RD, De Vuyst H, Gheit T, Snijders PJ, Tommasino M, Franceschi S, Clifford GM. Human papillomavirus 33 worldwide genetic variation and associated risk of cervical cancer. Virology. 2014;448:356-62.

27. Schiffman M, Wentzensen N. Human papillomavirus infection and the multistage carcinogenesis of cervical cancer. Cancer Epidemiol Biomark Prev. 2013;22:553-60.

28. Moschonas GD, Tsakogiannis D, Lamprou KA, Mastora E, Dimitriou TG, Kyriakopoulou Z, Kottaridi C, Karakitsos P, Markoulatos P. Association of codon 72 polymorphism of p53 with the severity of cervical dysplasia, E6T350G and HPV16 variant lineages in HPV16-infected women. J Med Microbiol. 2017;66:1358-65. 
29. Lichtig H, Algrisi M, Botzer LE, Abadi T, Verbitzky Y, Jackman A, Tommasino M, Zehbe I, Sherman L. HPV16 E6 natural variants exhibit different activities in functional assays relevant to the carcinogenic potential of E6. Virology. 2006:350:216-27.

30. Pham TTT, Bi X, Hoang HTT, Ishizaki A, Nguyen MTP, Nguyen CH, Nguyen HP, Pham TV, Ichimura H. Human papillomavirus genotypes and HPV16 E6/ E7 variants among patients with genital cancers in Vietnam. Jpn J Infect Dis. 2018;71:419-26.

31. Zhou Z, Yang H, Yang L, Yao Y, Dai S, Shi L, Li C, Yang L, Yan Z, Yao Y. Human papillomavirus type 16 E6 and E7 gene variations associated with cervical cancer in a Han Chinese population. Infect Genet Evol. 2019;73:13-20.

32. Yu JH, Shi WW, Zhou MY, Liu JM, Han QY, Xu HH. Genetic variability and oncogenic risk association of human papillomavirus type 58 E6 and E7 genes in Taizhou area, China. Gene. 2019;686:171-6.

33. Mirabello L, Yeager M, Yu K, Clifford GM, Xiao Y, Zhu B, Cullen M, Boland JF, Wentzensen N, Nelson CW, et al. HPV16 E7 genetic conservation is critical to carcinogenesis. Cell. 2017;170:1164-74 e1166.

34. Safaeian M, van Doorslaer K, Schiffman M, Chen Z, Rodriguez AC, Herrero R, Hildesheim A, Burk RD. Lack of heterogeneity of HPV16 E7 sequence compared with HPV31 and HPV73 may be related to its unique carcinogenic properties. Arch Virol. 2010;155:367-70.

35. Roman A, Munger K. The papillomavirus E7 proteins. Virology. 2013;445:138-68.

\section{Publisher's Note}

Springer Nature remains neutral with regard to jurisdictional claims in published maps and institutional affiliations.

Ready to submit your research? Choose BMC and benefit from:

- fast, convenient online submission

- thorough peer review by experienced researchers in your field

- rapid publication on acceptance

- support for research data, including large and complex data types

- gold Open Access which fosters wider collaboration and increased citations

- maximum visibility for your research: over $100 \mathrm{M}$ website views per year

At $\mathrm{BMC}$, research is always in progress.

Learn more biomedcentral.com/submissions 